\title{
MONITORAMENTO E CARACTERIZAÇÃO DA QUALIDADE DO RIBEIRÃO DO SERTÃO
}

\author{
I. F. de C. ROSAS ${ }^{1}$, L.F. SANTOS ${ }^{2}$, H.J. IZÁRIO FILHO ${ }^{3}$ \\ 1,2,3 Universidade de São Paulo, Escola de Engenharia de Lorena \\ E-mail para contato: isisfernanda@alunos.eel.usp.br
}

\begin{abstract}
RESUMO - A atual crise hídrica mundial e os diversos desastres ambientais, intensificados por práticas humanas indevidas, como a ocupação imprópria de encostas e o lançamento de resíduos nos corpos d'água, revelam urgência em relação à proteção das águas no país e no mundo. Diante dessa realidade, a sociedade acadêmica, junto aos cidadãos, possui papel fundamental no monitoramento dos rios e na verificação do cumprimento das leis ambientais. Dessa forma, o projeto em questão teve como objetivo verificar a qualidade das águas do Ribeirão do Sertão, localizado no município de Piquete - SP, através de análises e da comparação de parâmetros físico-químicos com valores de referência estabelecidos pela legislação. Através dos resultados, observou-se que alguns parâmetros não atenderam à Resolução 357/2005 do CONAMA para rio de classe 1. Alguns valores de $\mathrm{DBO}$, fósforo, $\mathrm{pH}$ e turbidez foram superiores aos limites definidos. Além disso, verificou-se um aumento das concentrações de sólidos e de óleos e graxas ao longo do tempo, provavelmente devido ao lançamento de efluentes industriais e ao despejo de óleo de cozinha no esgoto doméstico. Notouse ainda que o quarto ponto de coleta, localizado próximo a locais com lançamento de esgoto "in natura", é o mais afetado pelo lançamento de carga orgânica biodegradável e não biodegradável, apresentando os maiores valores de COT $(6,14 \pm 0,5$ mg.L-1), DBO $(6,40 \pm 0,5$ mg.L-1) e DQO $(23,29 \pm 4,1$ mg.L-1) e os menores de OD $(6,74 \pm 0,2 \mathrm{mg} . \mathrm{L}-1)$.
\end{abstract}

\section{INTRODUÇÃO}

A água, substância elementar que permitiu o surgimento, a evolução e a manutenção de toda a vida na Terra é também um recurso natural indispensável, desde a antiguidade, em atividades de agricultura, transporte e comércio e, atualmente, também no setor industrial e na geração de energia.

No entanto, verifica-se hoje um quadro de escassez hídrica de âmbito global, no qual três a quatro bilhões de pessoas no mundo não possuem acesso à água encanada e de qualidade confiável. Percebe-se ainda que fatores como o crescimento exponencial da população mundial e o decorrente aumento do consumo de água, aliados ao desperdício, à falta de planejamento do manejo adequado das águas e à poluição hídrica causada por ações humanas, comprometem cada vez mais a qualidade e a disponibilidade desse recurso fundamental (UNESCO, 2012). 
Diante desse contexto, torna-se urgente a necessidade da criação de políticas e legislações que obriguem a todos os países a se unirem na proteção dos recursos hídricos, tornando racional e estratégico o consumo desse bem natural no mundo. Já no âmbito nacional é essencial a atuação de toda a população, na fiscalização do cumprimento das leis ambientais e na cobrança de ações públicas, e principalmente, da sociedade acadêmica, no desenvolvimento de pesquisas comprobatórias acerca das condições reais da qualidade das águas, a fim de embasar pedidos de providências da comunidade junto aos governos.

Com isso, a presente pesquisa visou analisar, por meio de monitoramento e caracterização, as condições de um corpo d'água localizado no município Piquete, Estado de São Paulo: o Ribeirão do Sertão, que se enquadra na classificação de recursos hídricos de classse 1, de acordo com o Decreto Estadual 10.755/77.

Um dos motivos para a escolha da área de atuação é o fato de que o sistema de esgoto sanitário do Município de Piquete, localizado na porção central do Vale do Paraíba do Sul, é constituído apenas de rede coletora, de forma que todo o esgoto bruto coletado é lançado in natura nos corpos d'água da cidade. Além disso, há no Município uma série de problemas de alagamentos relacionados, por exemplo, a solapamentos de margens dos ribeirões e sedimentação de grande quantidade de materiais das mais diversas naturezas nos canais de água (CONSÓRCIO PLANSAN, 2010).

Além disso, os principais corpos d'água que cortam o Município são o Ribeirão do Sertão e o Ribeirão Benfica, principais afluentes do Ribeirão Piquete, que por sua vez, deságua no trecho paulista do Rio Paraíba do Sul, que se trata de um meio extremamente importante para o desenvolvimento da região em que se encontra, e até mesmo para abastecimento de alguns municípios, tornando ainda mais importante a área de estudo (CONSÓRCIO PLANSAN, 2010).

\section{METODOLOGIA}

A metodologia aplicada dividiu-se em três etapas: seleção da área de estudo; amostragem e preservação; e análises físico-químicas.

\subsection{Seleção da Área de Estudo}

Para efetuar a caracterizando do Ribeirão do Sertão foram selecionados 6 pontos de coleta (P1 a P6), apresentados na Figura 1 e distribuídos de forma que fosse possível avaliar a influência do lançamento de dejetos domésticos e industriais do município no corpo d'água ao longo de seu percurso.

Figura 1 - Pontos de coleta

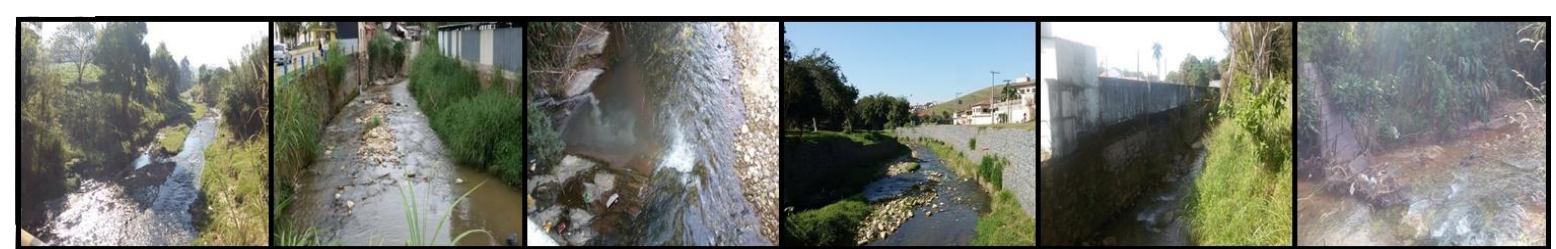

Fonte: próprio autor. 
Para isso, estabeleceu-se P1 na saída da cidade, a jusante do ponto P6, sendo este mais próximo à nascente do ribeirão, conforme ilustrado na Figura 2.

Figura 2 - Mapa de localização dos seis pontos de amostragem

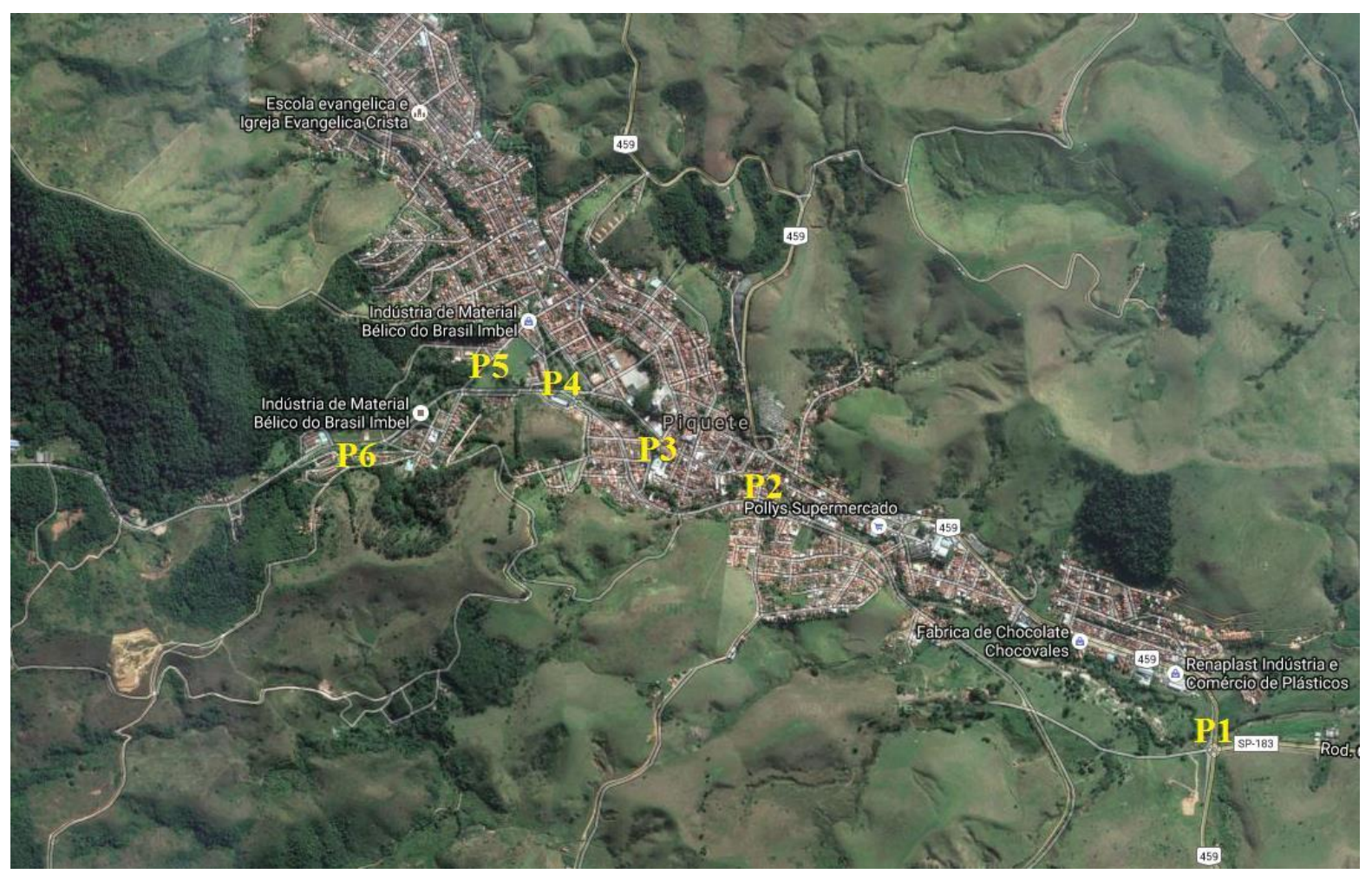

Fonte: adaptado de GOOGLE MAPS (2016).

\subsection{Amostragem e Preservação}

Coletou-se água do Ribeirão do Sertão em diferentes datas a fim de analisar a variação da composição hidrológica ao longo do tempo. A primeira coleta foi realizada em abril de 2016 e as demais em junho e julho do mesmo ano.

A coleta e a preservação das amostras de água seguiram os critérios determinados na Norma Técnica da NBR 9.898 - Preservação e técnicas de amostragem de efluentes líquidos e corpos receptores (ABNT, 1987).

As amostras foram coletadas com coletor apropriado e armazenadas em recipientes de vidro. Em seguida, foram encaminhadas ao Laboratório do Meio Ambiente da Escola de Engenharia de Lorena EEL/USP para efetuação das análises físico-químicas.

\subsection{Análises Físico-químicas}

A escolha dos parâmetros utilizados na caracterização do Ribeirão do Sertão baseou-se na importância desses índices físico-químicos para o meio ambiente e para a vida que nele habita, mas também na disponibilidade de equipamentos, métodos e reagentes no Laboratório de Meio Ambiente da Escola de Engenharia de Lorena (EEL/USP). 
Com isso, foram realizadas as seguintes análises: potencial hidrogeniônico $(\mathrm{pH})$, condutividade e temperatura, utilizando-se uma sonda multiparamétrica, modelo HI 9811-5; turbidez, utilizando-se um turbidímetro da TECNOPON, modelo TB 1000; OD, DBO 5,20 , DQO, fósforo, nitrogênio amoniacal e orgânico, COT, sólidos, óleos e graxas, sendo estes realizados através de métodos detalhados no Manual prático para as metodologias analíticas do laboratório de Meio Ambiente, elaborado por pesquisadores desse laboratório (Ferreira et al.,2015).

O manual citado, por sua vez, teve como base os métodos do Standard methods for the examination of water and wastewater (APHA, 2012).

Os resultados obtidos nas análises físico-química em questão foram então comparados com os valores de referência estabelecidos pela Resolução 357/2005 do CONAMA para um corpo d'água classe 1, que é o caso do Ribeirão do Sertão, como já citado.

\section{RESULTADOS E DISCUSSÃO}

A Tabela 1 apresenta as médias dos resultados das três coletas, obtidos para cada parâmetro de cada ponto, e os seus respectivos desvios padrões, bem como os valores de referência estabelecidos pela Resolução 357/2005 do CONAMA para corpos d'água classe 1.

A partir das análises realizadas e dos valores obtidos verificou-se que parâmetros como DBO, Fósforo e alguns valores de $\mathrm{pH}$ e de turbidez não se adequaram aos valores estabelecidos pela Resolução 357/2005 do CONAMA. Já os resultados OD e Nitrogênio Amoniacal atenderam à legislação.

Tabela 1 - Média dos resultados das três coletas realizadas

\begin{tabular}{|c|c|c|c|c|c|c|c|}
\hline Parâmetros físico-químicos & Valores de Referência & Ponto 1 & Ponto 2 & Ponto 3 & Ponto 4 & Ponto 5 & Ponto 6 \\
\hline Temperatura $\left({ }^{\circ} \mathrm{C}\right)$ & sem referência & $21,5 \pm 1,2$ & $21,4 \pm 1,6$ & $21,6 \pm 1,7$ & $21,7 \pm 1,6$ & $21,9 \pm 1,8$ & $21,8 \pm 2,2$ \\
\hline $\mathrm{pH}$ & 6,0 a 9,0 & $6,9 \pm 0,8$ & $6,6 \pm 0,7$ & $6,7 \pm 0,6$ & $6,7 \pm 0,6$ & $6,7 \pm 0,6$ & $6,6 \pm 0,6$ \\
\hline Condutividade $\left(\mu \mathrm{S} . \mathrm{cm}^{-1}\right)^{[a]}$ & sem referência & $147 \pm 124,2$ & $117 \pm 81,4$ & $143 \pm 127,0$ & $120 \pm 112,7$ & $153 \pm 144,3$ & $180 \pm 207,8$ \\
\hline Turbidez (NTU) ${ }^{[a]}$ & $<40$ & $4,89 \pm 4,2$ & $11,23 \pm 5,9$ & $122,53 \pm 196,1$ & $26,77 \pm 31,0$ & $21,28 \pm 25,4$ & $16,24 \pm 16,9$ \\
\hline $\mathrm{DQO}\left(\mathrm{mg} \cdot \mathrm{L}^{-1}\right)$ & sem referência & $6,82 \pm 2,4$ & $11,13 \pm 3,9$ & $17,55 \pm 6,6$ & $23,29 \pm 4,1$ & $14,79 \pm 1,1$ & $10,45 \pm 1,0$ \\
\hline $\mathrm{OD}\left(\mathrm{mg} \cdot \mathrm{L}^{-1}\right)$ & $<6,0$ & $7,19 \pm 0,2$ & $7,22 \pm 0,2$ & $8,28 \pm 0,1$ & $6,74 \pm 0,2$ & $8,24 \pm 0,2$ & $8,19 \pm 0,3$ \\
\hline TOC $\left(\mathrm{mg} \cdot \mathrm{L}^{-1}\right)$ & sem referência & $6,34 \pm 0,5$ & $5,98 \pm 0,4$ & $6,21 \pm 0,5$ & $6,74 \pm 0,5$ & $5,77 \pm 0,6$ & $4,43 \pm 0,8$ \\
\hline $\begin{array}{l}\text { Nitrogênio Amoniacal } \\
\left(\mathrm{mg} \cdot \mathrm{L}^{-1}\right)\end{array}$ & $\begin{array}{c}3,7(\mathrm{pH} \leq 7,5) \\
2,0(7,5<\mathrm{pH} \leq 8,0) \\
1,0(8,0<\mathrm{pH} \leq 8,5) \\
0,5(\mathrm{pH}>8,5)\end{array}$ & $0,27 \pm 0,10$ & $0,35 \pm 0,10$ & $0,46 \pm 0,10$ & $0,42 \pm 0,13$ & $0,15 \pm 0,07$ & $0,02 \pm 0,01$ \\
\hline Nitrogênio Orgânico (mg. $\mathrm{L}^{-1}$ ) & sem referência & $0,18 \pm 0,03$ & $0,12 \pm 0,03$ & $0,06 \pm 0,04$ & $0,14 \pm 0,03$ & $0,05 \pm 0,01$ & $0,02 \pm 0,01$ \\
\hline Fósforo Total (mg.L-1) & $<0,1$ & $0,27 \pm 0,03$ & $0,25 \pm 0,04$ & $0,41 \pm 0,01$ & $0,26 \pm 0,03$ & $0,11 \pm 0,02$ & $0,16 \pm 0,02$ \\
\hline $\mathrm{DBO}\left(\mathrm{mg} \cdot \mathrm{L}^{-1}\right)$ & $<3,0$ & $3,65 \pm 0,4$ & $4,44 \pm 0,3$ & $5,01 \pm 0,3$ & $6,40 \pm 0,5$ & $3,99 \pm 0,3$ & $3,71 \pm 0,4$ \\
\hline Sólidos Totais $\left(\mathrm{mg} \cdot \mathrm{L}^{-1}\right)^{[a]}$ & sem referência & $91,40 \pm 105,3$ & $113,20 \pm 51,9$ & $162,03 \pm 96,6$ & $136,10 \pm 74,1$ & $159,86 \pm 117,1$ & $186,31 \pm 167,5$ \\
\hline Sólidos Totais Fixos $\left(\mathrm{mg} \cdot \mathrm{L}^{-1}\right)^{[a]}$ & sem referência & $56,73 \pm 65,2$ & $66,40 \pm 34,3$ & $107,87 \pm 70,3$ & $89,27 \pm 51,0$ & $89,50 \pm 60,8$ & $114,64 \pm 92,0$ \\
\hline Sólidos Totais Voláteis $\left(\mathrm{mg} \mathrm{L}^{-1}\right)^{[\mathrm{a}]}$ & sem referência & $34,67 \pm 40,2$ & $46,80 \pm 17,6$ & $54,17 \pm 28,5$ & $46,83 \pm 23,2$ & $70,36 \pm 56,9$ & $71,67 \pm 75,5$ \\
\hline Óleos e Graxas $\left(m g \cdot L^{-1}\right)^{[a]}$ & Virtualmente ausentes & $27,25 \pm 1,5$ & $11,37 \pm 3,9$ & $28,01 \pm 2,8$ & $22,16 \pm 2,4$ & $14,59 \pm 4,4$ & $27,89 \pm 4,9$ \\
\hline
\end{tabular}

[a] - análises que apresentaram discrepâncias entre as coletas possivelmente devido a influências da sazonalidade e das atividades industriais no município.

Fonte: próprio autor.

Além disso, verificou-se que as concentrações de óleos e graxas no corpo d'água tiveram um aumento significativo ao longo do tempo, o que se deve, possivelmente, ao 
despejo de óleo de cozinha no esgoto doméstico e/ou ao lançamento de efluentes industriais na água. O mesmo observou-se para a concentração de sólidos ao longo do tempo, o que também pode estar relacionado ao descarte de resíduos industriais.

Notou-se ainda que o quarto ponto de coleta, situado no centro do Município e localizado próximo a locais com lançamento de esgoto "in natura", é o mais afetado pelo lançamento de carga orgânica biodegradável e não biodegradável, apresentando os valores mais elevados de COT, DBO e DQO e os menores de OD.

\section{CONCLUSÃO}

Constatou-se que, embora o Ribeirão do Sertão possua certa capacidade de autodepuração e possibilidade de gradualmente degradar a matéria orgânica nele presente, existem medidas para melhorar e preservar as condições hídricas do Município. Uma alternativa é a implantação do tratamento de esgoto no município, considerando que o lançamento de esgoto in natura é o que mais tem contribuído para o aumento da carga de poluentes no corpo hídrico.

A partir dos resultados obtidos através de determinações analíticas e observações realizadas durante as coletas, a respeito dos lançamentos de esgoto doméstico in natura, constatou-se que embora o Ribeirão do Sertão possua certa capacidade de autodepuração e possibilidade de gradualmente degradar a matéria orgânica nele presente, existem medidas para melhorar e preservar as condições hídricas do Município. Uma alternativa é a implantação do tratamento de esgoto no município, considerando que o lançamento de esgoto in natura é o que mais tem contribuído para o aumento da carga de poluentes no corpo hídrico.

\section{NOMENCLATURA}

DBO Demanda Bioquímica de Oxigênio

DQO Demanda Química de Oxigênio

COT Carbono Orgânico Total

OD Oxigênio Dissolvido

\section{REFERÊNCIAS}

ABNT. ASSOCIAÇÃO BRASILEIRA DE NORMAS TÉCNICAS. NBR 9.898: Preservação e técnicas de amostragem de efluentes líquidos e corpos receptores. Rio de Janeiro, 1987.

APHA. AMERICAN PUBLIC HEALTH ASSOCIATION. Standard methods for the examination of water and wastewater. 22th ed. Washington, 2012.

BRASIL. Ministério do Meio Ambiente. Conselho Nacional do Meio Ambiente (CONAMA). Resolução $n^{\circ}$ 357, de 17 de março de 2005. Disponível em <http://www.mma.gov.br/port/conama/res/res05/res35705.pdf>. Acesso em $13 \mathrm{de}$ janeiro de 2016. 
CONSÓRCIO PLANSAN 123. Plano Municipal Integrado de Saneamento Básico Piquete. 2010. Disponível em: <http://www.saneamento.sp.gov.br/ PMS/UGRHI02/PMS_PIQUETE.pdf >. Acesso em: 12 de janeiro de 2016.

FERREIRA, G. A.; IZÁRIO FILHO, H. J. Manual prático para as metodologias analíticas do laboratório de Meio Ambiente. Departamento de ciências básicas e ambientais da Escola de Engenharia de Lorena (EEL - USP). Lorena, 2015.

SÃO PAULO (ESTADO) Decreto Estadual 10.755/77. Disponível em: <http://portalpnqa.ana.gov.br/Publicacao/Decreto\%20n\%C2\%BA\%2010.755\%20 de\%2022\%20de\%20novembro\%20de\%201977.pdf>. Acesso em: 21 de janeiro de 2016.

UNESCO. ORGANIZAÇÃO DAS NAÇÕES UNIDAS PARA A EDUCAÇÃO, A CIÊNCIA E A CULTURA. Fatos e dados - Relatório Mundial das Nações Unidas sobre o desenvolvimento dos recursos hídricos 4: O manejo dos recursos hídricos em condições de incerteza e risco. Ed CNPq/IBICT/UNESCO, $9^{\circ}$ andar, Brasília, 2012. Disponível em: <http://unesdoc.unesco.org/images/0021/ 002154/215492por.pdf>. Acesso em: 12 de agosto de 2016 